OPEN ACCESS

Edited by:

Dylan van der Schyff,

University of Melbourne, Australia

Reviewed by:

Daniel Shevock,

Penn State Altoona, United States June Boyce-Tillman

University of Winchester, United Kingdom

*Correspondence: Tawnya D. Smith tdsmith7@bu.edu

Specialty section: This article was submitted to Educational Psychology, a section of the journa

Frontiers in Education

Received: 02 January 2021 Accepted: 29 March 2021

Published: 16 April 2021

Citation:

Smith TD (2021) Music Education for Surviving and Thriving: Cultivating Children's Wonder, Senses, Emotional Wellbeing, and Wild Nature as a Means to Discover and Fulfill Their Life's Purpose.

Front. Educ. 6:648799. doi: 10.3389/feduc.2021.648799

\section{Music Education for Surviving and Thriving: Cultivating Children's Wonder, Senses, Emotional Wellbeing, and Wild Nature as a Means to Discover and Fulfill Their Life's Purpose}

\author{
Tawnya D. Smith* \\ Music Education, School of Music, College of Fine Arts, Boston University, Boston, MA, United States
}

Children who are supported throughout childhood and adolescence to both maintain their sense of wonder in nature, and honor and explore their wild human nature, are well positioned to mature into soulcentric adults capable of living into their purpose in service to both their culture and the whole of life. However, our society's ecocidal culture and unjust institutions often replicate oppressions and promote egocentric behaviors that preclude thriving. Additionally, many children are alienated from nature and are thought to have nature-deficit disorder, which can include both mental and physical maladies. In this article I explore conceptions of ecojustice education to further illustrate pathways for curriculum development in music education that might encourage children and adolescents to maintain their sense of wonder in nature, fully develop their sensory capacities, support their mental and emotional wellbeing, attune more carefully to their wild nature and soul's purpose, and contribute to the environmental and social commons-all which might support human flourishing and the continued survival of our species.

\footnotetext{
Keywords: ecojustice music education, eudaimonia, wonder, sensory education, emotional wellbeing, human development, cultural and environmental commons
}

\section{INTRODUCTION}

Many of us have enjoyed engaging in music making as a means to generate happiness and connection with others; however, our taken-for-granted assumptions about the potential to realize such eudaimonic aspirations are set to be challenged if the projections in the Intergovernmental Panel on Climate Change report (Intergovernmental Panel on Climate Change [IPCC], 2020) are correct. Such dire warnings from scientists make it clear that without immediate and radical change, our ability to create a good life is set to degrade in unprecedented ways within a few decades. A growing consensus of experts believe that there is sufficient evidence to suggest that we are currently headed for both ecosystem collapse (Swiss Re Group, 2020) and subsequent societal collapse (Spratt and Dunlop, 2019; Weyhenmeyer et al., 2020). Therefore, the systems in which musicians and music educators function and are funded are likely to erode as we see 
increases in extreme weather events, food and water shortages, physical displacement (where entire communities are forced to relocate to more habitable lands or climates), and as available resources are diverted toward adaptation and human survival. In times of crisis (and for those who are already routinely living with the violence of environmental destruction), music is likely a critical outlet for the expression of mourning, the expelling of the shock of trauma, creating community solidarity, and protest; however, such survival purposes for music making are not the primary purposes that more privileged musicians have come to enjoy in times of stability. As we face the prospect of extreme adaptation and the need to heal ourselves and our planet, it seems prudent to expand music education curricula to embrace practices that build both individual and community resilience as a means to ensure the continued possibility of flourishing.

Although it is a matter of debate as to whether we have time to reverse the damage we have caused to the earth, most scientists agree that our changing weather, the rapid extinction of otherthan-human species, the degradation of the soil in which we grow crops, ecosystem collapse, plastic pollution on both land and sea, and sea-level rise are amongst a growing list of signs that we have altered the earth to such an extent that we risk destabilizing the natural systems of which we rely to survive and thrive (Figueres and Rivett-Carnac, 2020). For the purpose of this article, I am choosing to assume that our collective will to live will propel us forward toward the radical change that we need make in order to ensure that human civilization not only survives but also learns to flourish within the limitations of the ecosystem of which we are a part. This is not a given, however, and our survival depends upon a majority of people moving away from ecocidal policies and habits to life-giving ones-and in short order.

It is also important to note that environmental degradation is already taking the lives of both children and adults, and that global climate-related deaths are projected to increase by 250,000 per year from the year 2030 and beyond (World Health Organization (WHO), 2020). Air pollution alone is linked to childhood asthma (Environmental Protection Agency, 2018) and many types of cancer (American Association for Cancer Research, 2020). In addition to asthma, climate change is thought to cause worsening allergy seasons, increases in heat-related illness, and changes in brain development, as well as low birth weight and preterm pregnancies (Harvard T. H. Chan School of Public Health, 2020). Children who live in more polluted areas or in places with a higher prevalence of extreme weather events are especially at risk of climaterelated disruptions to their lives and education (Martusewicz et al., 2015). It is for this reason that I assert that educators consider seriously their role in preparing children both for the multiple crises they have inherited through no fault of their own, and to think and act in ways that are sustainable for human survival.

As music educators consider how to shift priorities accordingly (Boyce-Tillman, 2004, 2016, 2020; Bates, 2013; Younker and Bracken, 2015; Adams and Beauchamp, 2018), many current assumptions about what music education is for are necessarily challenged (Morton, 2012). Shevock (2015,
2018) argues for an eco-literate pedagogy as an extension of Orr's (1992) conceptions of eco-literacy, and situates such a pedagogy in an interdisciplinary context that welcomes Indigenous and spiritual knowledge. While Shevock's theoretical and philosophical ideas point the way to how we might begin to reprioritize music education-and there is some evidence that these ideas are being applied (Snyder, 2018)-the widespread application of eco-literate pedagogical practices has not yet been realized. Further, it is Orr (2020) who, in a recent chapter exploring eudaimonic ideals, urges music educators to "seek new ways of musicking to harness the great powers of musicophila and biophilia to alert, awaken, and inspire us to defend the habitability of the Earth" (p. 57), which is a call from outside of our field to join other disciplines in the race to defend life on earth.

Given the urgency of the environmental crises we face, I assert that a radical re-examination of our purposes and adaptation of our practices is the very least that educators can do, given that we have failed to ensure the conditions for thriving for our youngest citizens. Reassessing our purposes is especially critical given the rise in environmental degradation related mental health concerns such as eco-fear (Buzzell and Chalquist, 2019) and depression, both of which clinicians are attributing to environmental related causes, as well as the inability of youth to vision a world of stability and thriving (American Psychological Association, 2017; Harvard T. H. Chan School of Public Health, 2020).

In this article, I argue that such a shift in the purposes of music education is aligned with Smith and Silverman's (2020) orientation toward eudaimonism and the pathways that they have identified to ensure human flourishing through music:

1. That the world is horribly unjust and that recognizing our place in the global system of brutal capitalist plutocracy may help us to envision and act for more equitable and just world;

2. Taking part in music-making activity that curates mutually flourishing communities for individuals and the collective flourish and thrive and feel the meaningfulness created by an for one another; and

3. Curating spaces for musicmaking, where flourishing through learning is the primary objective.

I argue that such a radical re-visioning of music education is needed to provide the necessary interdisciplinary and experiential learning that would help children to maintain their sense of wonder in nature; to fully develop their sensory capacities; to maintain, and if necessary, repair their mental health; and to attune more carefully to their wild nature and soul's purpose. Finally, I situate these individual concerns within relational and community concerns by considering how music education might also contribute to the project of stewarding and regenerating the environmental and cultural commons (Martusewicz et al., 2015).

\section{A Radical Shift in Thinking}

In their book, The Future We Choose: Surviving the Climate Crisis, Figueres and Rivett-Carnac (2020) project two futures. The first depiction is a dire warning about societal collapse if we continue 
with business as usual, and the second is a future where we will have adapted to sustainable and restorative practices that ensure a future for human civilization yet we will mourn some inevitable losses. The authors suggest that in order to realize the second possibility we must embrace a radical shift in our thinking:

To survive and thrive, we must understand ourselves to be inextricably connected to all of nature. We need to cultivate a deep and abiding sense of stewardship. This transformation begins with the individual. Who we are and how we show up in the world defines how we work with others, how we interact with our surroundings, and ultimately the future we co-create (Chapter 4, paragraph 10).

The authors suggest that we need to adopt three mindsets: stubborn optimism, endless abundance, and radical regeneration. Specifically, stubborn optimism is defined as a rejection of denial, pessimism, and attitudes of blame or helplessness that interfere with our ability to engage in creating a better future. A mindset of endless abundance is one that rejects a zerosum mentality based upon competition and scarcity, and instead strengthens the human capacity to provide mutual assistance in times of crisis and to work collaboratively to create abundance. Radical regeneration is a mindset that rejects the colonial discourse of extraction and exploitation and instead embraces a regenerative one that acknowledges our dependence upon, and interconnectedness with, the planetary life-support system. As we as educators consider our vulnerable future, it is only logical that we consider ways to align our curricula and practices to introduce and encourage the formation of such mindsets.

Ecojustice educators Martusewicz et al. (2015) offer a pedagogy of responsibility that aligns well with this aim. The authors assert, "Schools currently help to reproduce a culture and economic system whose short-term profit motive and ideology of unlimited growth have created a society that dangerously overshoots the carrying capacity of the bio-systems depended upon for life" ( $p, 19)$. Alternatively, they suggest that a responsible pedagogy is one that aims to "develop citizens who can actively work toward a democratic and sustainable society" that both "values cultural diversity" and "the essential role that bio-diversity plays in the very possibility of living systems" (p. 19). The purposes of education, then, are informed with the acknowledgment that the exploitation of both humans and the earth are intersectional ills linked to unsustainable thinking that has long been a part of the discourse of Western cultures and that needs to change for our continued survival.

To interrupt the thinking and resultant behaviors that are destroying both people and planet, Martusewicz et al. (2015) suggest that we need to recognize the role of "language, dualism, and hierarchized thinking" (p. 57) in our society. Buried into Western thought and language are value hierarchies that position one side of a dualism as superior to the other. Examples include "man/woman; culture/nature; reason/emotion; mind/body; etc." (p. 57). Such value hierarchies create an unquestioned invented superiority that along with common metaphors contribute to centric thinking (Plumwood, 2002). For example, Martusewicz et al. (2015) point out that the phrase "the developed world" positions such countries in the superior position but fails to acknowledge that less developed nations may be "appropriately developed" in terms of sustainability or that developed countries might be "overdeveloped." Together these form a "logic of domination" (Warren, 1998) that is based upon the premise that the physical and emotional are associated with the natural world, while the mental is associated with culture. This premise is paired with "the assumption that whatever is identified with nature and the realm of the physical is inferior to what is cultural and thus human" (p. 63). Together these two premises create false conclusions that "under[ly] the acceptance and continuation of class inequality, along with gender and race inequalities, and other forms of social degradation, and ecological devastation" (p. 63).

Martusewicz et al. (2015) go on to argue that the resultant discourses in modernity have created worldviews that are "a combination of linguistically created ideas" that while are invented "take on the function of truth" (p. 66). Such metaphors of the discourse of modernity include "individualism, mechanism, progress, rationalism/scientism, commodification, consumerism, anthropocentrism, androcentrism, and ethnocentrism," (p. 66-67) which underpin capitalism and socialism-both of which function with the same logic of domination and have historically been devastating to both people and earth. These ideas also inform music education traditions, practices, and structures in ways to which we, as music educators, are just beginning to awaken. For example, in a critique of Shevock's (2018) ecoliterate pedagogy, Vaugeois (2019) challenges music educators to use the music classroom as a place:

to explore a full range of musics of resistance-as a means to listen to voices not necessarily visible in one's 'place,' and a means to explore the institutional structures, and economic interests, that hold gender, race and class oppression, along with resistance to climate change mitigation, in place (p. 609).

Such an aim and extension of eco-literate pedagogy aligns with Martusewicz et al. (2015) conceptions of ecojustice education. Similarly, it is critical that we confront oppressive ideologies and structures in order to evolve past such thinking and to create discourses that underpin sustainable cultures Figueres and Rivett-Carnac (2020). Specifically, we need to identify, remove, and replace thought forms, assumptions, and actions that stem from the logic of domination.

To create different mindsets, Martusewicz et al. (2015) suggest non-native educators learn from Indigenous peoples who have historically maintained sustainable cultures. They are careful to point out that learning from Indigenous persons is different than appropriating their knowledge or traditions. The authors suggest that an appropriate course of action is to consider the overarching ideas that these cultures share 
and consider how those ideas might apply to our local contexts. Common ideas amongst many Indigenous cultures include holism or seeing all things as being interconnected; viewing change as something to be controlled and evaluated for both future consequences and with respect for traditions; valuing multiple ways of knowing; and engaging in noncommodified traditions such as barter that emphasize "face-toface relationships, community, and intergenerational knowledge" (p. 84). These and other related values could replace the logic of domination throughout the curriculum to help support a transition to ecojustice learning.

\section{REMOVING THE LOGIC OF DOMINATION FROM MUSIC EDUCATION}

If the assumptions and patterns of thinking that we inherited are ecocidal and will eventually preclude our ability to flourish, it is important to consider ways of thinking about music making and music learning that free us from the assumptions and patterns aligned with the dominant ecocidal worldview. Although changing how we make or teach music alone will not prevent environmental destruction, adopting new patterns of thought that are sustainable, life-giving, and in harmony with the natural world are critical for our continued survival. Different ideas and practices are particularly important for our children to learn and embody in ways that we as adults have failed to do; enacting new possibilities will literally be a matter of life and death for today's children and youth as they contend with the results of our shortcomings during their adult lives.

Ecophilosophers Macy and Brown (2014) suggest that we can either position ourselves in a Business-as-Usual mindset that reproduces ecocidal actions; get caught up in the story of The Great Unraveling (by focusing upon and getting stuck ruminating about alarming climate news); or instead participate in The Great Turning-the project to transition from an industrial growth society to a life-sustaining one (as referenced in Figueres and Rivett-Carnac, 2020, above). How, then, might we as musicians and music educators position ourselves within the project of The Great Turning? There are a multitude of ways that we might do so at both the personal and collective level. At the personal level, we might look for ways to reestablish our connection with our self and nature. At the collective level it seems critical that we identify and replace all practices and structures that align with the logic of domination.

Although there is a deepening conversation in our field around a number of social justice issues, it has only been in the past two decades that the topic of sustainability and ecological considerations have gained more prominence. The most comprehensive offering is Shevock's (2018) EcoLiterate Pedagogy, which provides important philosophical considerations. An invitation to develop further scholarship and practices in this area was offered by the adoption of article nine to the MayDay Group's Action Ideals in 2020, which calls for an "environmentally regenerative music education attuned to cultural and physical commons, pollution-free soundscapes, the inherent value of other-than-human being, and people musicking for environmental activism" (MayDay Group, 2020). This action ideal aligns well with Martusewicz et al. (2015) assertion that all educational endeavors support the formation and maintenance of the environmental and cultural commons (described further below). However, before considering music education's role in schooling for the commons, I am reminded by Figueres and Rivett-Carnac (2020) that "Who we are and how we show up in the world" impacts our ability to steward and contribute to the commons. It is for this reason that I offer four purposes for music education that might prepare and nourish us individually as we participate in the Great Turning. Specifically, I propose a music education that might encourage children (and all people) to maintain their sense of wonder in nature, to fully develop their sensory capacities, to support their psychospiritual wellbeing, and to foster soulcentric maturation.

\section{Music Education That Supports a Child's Sense of Wonder in Nature}

And thought, if it's not open to wonder, can be limiting, destructive and very, very dangerous. If you look at thought as a circle, and if half of the arc of the circle is the infusion of wonder, then the thought will be kind, it will be gracious, and it will also be compassionate, because wonder and compassion are sisters (O’Donohue, 2015, p. 7)

Most everyone has at least one memory of being awestruck in nature and being completely transformed by the experience. Some intentionally seek out such experiences, whether catching a glimpse of a full moon while walking down a busy street or retreating to some pristine location. Often such experiences involve a complete immersion into one's senses and a temporary departure from our ordinary thoughts and mood, which allows us an opportunity to embody a sense of wonder and to explore our imaginations. Rachel Carson, matriarch of the environmental movement, wrote about the importance of nurturing children's connection with nature, and hoped adults might enliven "a sense of wonder so indestructible that it would last throughout life, as an unfailing antidote against the boredom and disenchantments of later years, the sterile preoccupation with things that are artificial, the alienation from the sources of our strength" (1956, p. 44). In this way, maintaining a sense of wonder might be seen as an essential prerequisite to thriving and flourishing.

Although children are thought to embody wonder and imagination to a greater extent than most adults, access to technology early in life may be restricting rather than expanding children's abilities in ways that spending more time in nature might serve to counterbalance (Louv, 2012). To stimulate children's creative capacities, many scholars theorize that children need play spaces with many "loose parts" (Gibson et al., 2017). Louv (2012) suggests that technology only supplies a predetermined number of loose parts because of the limitations of programming. Conversely, nature provides a much greater number of loose parts, and has been found 
to foster "child-initiated interaction" and allow teachers to "build upon children's interests" (Waters and Maynard, 2010, p. 473). Similarly, Adams and Beauchamp (2018) found that primary school students who made music outdoors were more connected to their emotions and senses and were empowered by a sense of freedom and agency. They suggest these particular elements created a "'vortex' effect, potentially drawing the children into a state of liminality and peak experience, before achieving a state of calm focus" (p. 50). The authors found that the outdoor location of music making facilitated these possibilities and the result was an expansion of the children's imaginative abilities. Outdoor sound exploration may offer children more "loose parts" and opportunities to experience wonder and imagination because nature does not limit musical creativity to technologically predetermined options whether they be traditional acoustic instruments or preset electronically generated sounds.

\section{A Soundscape Ecology Perspective of Music Learning}

A way that educators might restructure music education experiences to better foster the conditions for wonder could be to "relegate unsustainable practices to the compost pile" (Shevock, 2018, p. 31), such as our anthropocentric definition of music. Rather than solely learning about human-generated sound or the anthropophony, music education could include music generated by other-than-human sources such as those in the biophony (those made by the floura or fauna), and geophony (sounds made by weather or geological features) (Pijanowski et al., 2011). Without advocating for a nature-based approach per se, Recharte (2019) argues for de-centering music from music education in lieu of a "sound education," which would allow for the cultivation of "a broad understanding of relationality within ecologies of human and non-human entities" (p. 1). Similarly, Matsunobu (2013) describes instances where musicians experienced "moments of perceiving music as nature, merging the self into the cosmos, and realizing the holistic, organic dimensions of life" (p. 64-65). These moments illustrate a more inclusive approach than Western anthropocentric conceptions, which view music made by humans as separate from that of the other-than-human world. Rather, music created by humans might be seen as a part of the holistic earthly soundscape.

The idea of attuning to natural soundscapes is not a novel one. Shevock (2018) includes soundscapes as a part of his essential structure for eco-literate pedagogy, and reminds us that spirituality-based music educator Satis Coleman's creative music method of the 1920s included such ideas. In the 1970s, concurrent with the rise of the environmental movement, Schafer (1977) invited musicians, educators, and environmentalists to attend to ambient soundscapes as he saw the encroachment of human-made sound as a neglected topic. Many educators have applied Schafer's ideas in music settings such as informal music learning (Heckel, 2017), free improvisation (Huovinen and Kuusinen, 2006), elementary school (Ward, 2009), secondary school (Imada, 2019), undergraduate music history (Black and Bohlman, 2017; Galloway, 2017), music composition (Friesen,
2012), as well as interdisciplinary settings (Younker and Bracken, 2015; Akbari, 2016).

Attuning and interacting with natural soundscapes may afford children opportunities to cultivate deeper sensitivities to sound. This may be particularly the case because in louder, humanmade soundscapes individuals tend to expend energy blocking out disruptive sounds rather than opening to the nuances and particulars that can be heard in natural settings (Louv, 2012). A soundscape-ecology perspective of music learning might also prevent children from identifying exclusively with human cultural conceptions of music and cause them to form an identity that is separated from the earth-a chief concern of Carson (1956) who understood that such a mental separation was necessary to justify the domination of the earth.

A soundscape ecology approach to music learning might be understood as an interdisciplinary connection with the natural, biological, and acoustical sciences; however, it might also be seen as a reclaiming of an Indigenous form of sound-knowing that was essential to our ancestors' survival and might be key to our adaptation to a rapidly changing climate. In either case, music education practices that expand our definition of music to include the music created by other-than-human means might help us to be better attuned and responsive to the needs of both humans and other-than-humans in our ecosystem.

\section{Music Education for the Cultivation of the Senses}

Beyond the benefits of wonder and soundscape attunement, nature immersion may be an untapped opportunity for music educators to help students cultivate deeper sensitivities to sound as well as to develop their other sensory capacities. According to Louv $(2008,2012)$, a lack of access to natural spaces and our culture's shift to ubiquitous use of technology has resulted in a dulling of our sensory capacities. Louv (2008) coined the term "nature-deficit disorder" not as a diagnostic, but as a means to call our attention to our atrophying awareness, which is characterized by a "diminished use of the senses, attention difficulties, and higher rates of physical and emotional illnesses" (p. 36). Such dulling of our sensory abilities and awareness stands to negatively impact our engagement with, and participation in, music making, as well as our ability to individually and collectively engage in the flourishing, thriving, and meaning making that Smith and Silverman (2020) suggest as the second pathway to realize eudaimonic aims.

According to Louv (2012), spending time outdoors can increase our ability to detect subtle changes in our environment, which may make us more alert to danger and cultivate a type of hyperawareness that-unlike the dissociated hypervigilance associated with trauma-is a more centered and embodied state of awareness. Outdoor time is also thought to enhance intelligence because hyperawareness and an increased ability to collect information through the senses might provide more information from which to think and act, and natural environments may "stimulate our ability to pay attention, think clearly, and be more creative, even in dense urban neighborhoods" (p. 27). 
Nature can afford us opportunities to engage in all of our senses simultaneously, which may also increase our learning capacities and engagement in life because our senses work interdependently in a fully embodied way (Louv, 2012). In addition to our five basic senses, it is thought that we have many more. For example, Cohen (1997) —an applied ecopychologist, musician, and nature-connection specialist-has identified 54 distinct human senses categorized into four areas (radiation, feeling, chemical, and mental) that can be cultivated through nature experiences. In addition to becoming aware of our full sensory capacities, Louv (2012) reminds us that our senses are capable of more than we think, given that some humans have developed advanced sensory abilities that are more typically associated with other-than-human species. If many children and adults are experiencing a dulling of the senses due to a lack of time outdoors, and if being outdoors can cultivate hyperawareness, enhance intelligence, and improve the ability to concentrate and create-and given that our sensory capabilities are likely underdeveloped-it seems logical that these deficits need to be addressed if our aim is to shift our priorities and mindsets to participate in The Great Turning and create the conditions for flourishing.

As music educators, it has traditionally been our business to enhance the sensory abilities of children specifically related to listening and tactile senses. But what if we applied our pedagogical skills to the larger project of sensory cultivation and partnered with the earth as a means to enhance our capabilities? Perhaps a better question would be, are we willing to miss the profound opportunity to deepen and liven the sensory capabilities of children by exclusively focusing upon making music indoors with or without technology? If we were to view ourselves as facilitators of sensory development in addition to our role as culture-bearers of the music traditions, we might be more able to create sonic engagements that do not bifurcate mind from body, mind from heart, or elevate human thinking above the wisdom of the earth and other-than-human forms of intelligence. Specifically, by reimagining our role and purpose, we might be better able to break from the status quo and disrupt practices that separate children from their relationship with or identity as the earth, dull children's sensory capacities, and silo the arts and sciences-three concerns we need to address in order to help prepare children for the rapid adaptation and change that they will face.

\section{Music Education for the Purpose of Psychospiritual Wellbeing}

Nature offers healing for a child living in a destructive family or neighborhood. It serves as a blank slate upon which a child draws and reinterprets the culture's fantasies. Nature inspires creativity in a child by demanding visualization and the full use of the senses. Given a chance, a child will bring the confusion of the world to the woods, wash it in the creek, turn it over to see what lives on the unseen side of that confusion. Nature can frighten children, too, and this fright serves a purpose. In nature, a child finds freedom, fantasy, and privacy: a place distant from the adult word, a separate peace (Louv, 2008, p. 6).

According to Burke et al. (2018), direct and indirect impacts of climate change have been found to harm the mental health of children, resulting in "PTSD, depression, anxiety, phobias, sleep disorders, attachment disorders, and substance abuse" (p. 34). Impacts of climate change have been found to cause problems with "emotion regulation, cognition, learning, behavior, language development, and academic performance" (p. 34) which often lead to mental health challenges in adulthood. Children also demonstrate higher levels of concern than many adults (Harvard T. H. Chan School of Public Health, 2020) when they are confronted with news about extreme weather events or with the prospect of climate change, degrading social and ecological stability, or human extinction. For example, Martusewicz et al. (2015) report that when they discuss ecojustice issues with undergraduates the students often say that such issues are "overwhelmingly depressing, so much so that they cannot bear to pay attention" (p. 286). Perhaps environmental degradation and climate change is one of the reasons that the rates of anxiety (Centers for Disease Control and Prevention, 2020), depression (Mojtabai et al., 2016), and suicide ideation (Miron et al., 2019) have been on the increase for children and adolescents over the past few decades.

Music making has been a means to promote mental, emotional, and spiritual healing since time immemorial, yet music educators have traditionally privileged content learning and performance objectives over music making for wellbeing or spiritual purposes (Boyce-Tillman, 2004). During the COVID-19 pandemic, there have been many anecdotal reports of individuals, communities, and music teachers redirecting their aims to afford more emphasis upon music for wellbeing, positive coping, and healing, which if expanded and more widely adopted might establish a more wellrounded approach to music learning in schools. Boyce-Tillman (2020) suggests that music teachers consider including all five phenomenographical domains of music making as a means to promote eudaimonic aims: materials (the body, sound production, and acoustics); expression (intrinsic and extrinsic feelings); construction (production concerns); values (context and cultural meanings); and spirituality/liminality (distinct knowing where time and space operate differently). Doing so might help us to see our role as less of a music director or teacher, and more as a steward of nutritive musical experiences who resists potentially harmful social comparisons and value judgments and embraces caring and compassionate actions (Hendricks, 2018).

According to the Harvard T. H. Chan School of Public Health (2020), it will be necessary for adults to provide more support to children in order to promote resilience in the face of the toxic stress caused by the climate crises. The authors of this report suggest that caregivers provide consistent involvement in children's lives as well as model healthy risk-taking and persistence. They also recommend that professional development be provided to teachers so that they can properly care for students who have experienced trauma. 
In a way more directly addressing the likely cause of emotional distress, Brown (2016) has adapted for children The Work that Reconnects, an approach that Macy and Brown (2014) developed for working with adults coping with climate grief and despair. This approach is seen as a spiral of experiences that directs participants through activities that help them to (a) recall the gratitude they have for the gift of life, (b) "honor the pain that they have for the world," (c) see the situation with "new eyes," and (d) identify actions that they can take. Brown asserts that it is important for adults not to remain silent about the crises we face, and instead help children to better connect with nature, learn to identify and express their feelings, support them to identify and carry out appropriate actions, and share with them the actions that adults are taking.

I was reminded of the importance of sharing my own efforts when an undergraduate advisee stated how hard it was to concentrate on instrumental methods and techniques when all she could think about was how the impending climate crisis might make such knowledge irrelevant. Similarly, a graduate student admitted that he had considered leaving the field to work more directly to address the crisis. If our students are preoccupied by-or experiencing mental or emotional health challenges as a result of-the climate crises, it may become increasingly important for music educators to integrate approaches used by music therapists in order to create learning spaces that promote wellbeing and do not exacerbate mental health issues. Although music educators are not qualified to conduct therapy, there is likely much we could learn about how to create trauma-sensitive classroom environments, promote healthier relationships between and with students, and increase our capacity to provide unconditional attention to our students. Similarly, Boyce-Tillman (2016), argues for music educators to consider music therapy approaches that allow for self-exploration and the relationship between intrinsic and extrinsic meanings for music making. Such an expansion might allow space for both students and teachers to express emotions in helpful ways and realize music's potential to communicate individual meanings to others - a skill relevant to individual and collective mental wellbeing. Additionally, educators might need to devote more time to healing their own trauma and attending to their mental health, developing greater social-emotional competence (Jennings, 2019) and non-violent communication practices (Rosenberg, 2003).

\section{Music Education for the Purpose of Soulcentric Maturation}

To consider the psychospiritual needs of children that may not be met in current music learning contexts, I turn to Plotkin's (2008) Nature of the Human Soul framework, which compares egocentric vs. a soulcentric human maturation. Plotkin defines soul as a person or thing's ultimate place in the world, and suggests that all "creatures, objects, events and relationships" therefore have soul (p. 30). A soulcentric orientation is one that occurs once a person is initiated through taking part in a ritual (ideally during adolescence) that marks the end of childhood and the beginning of adulthood. A successful initiation is one where an individual becomes aware of their ultimate place in both the ecological and social worlds and is therefore able to embody their unique psycho-ecological niche. In contrast, an egocentric orientation is one where the ego is unaware of the soul's purpose and therefore is "an agent for itself" (p. 43).

Plotkin (2008) asserts that Western and Westernized cultures reinforce "a way of life that emphasizes social acceptability, materialism, self-centered individualism, and superficial security rather than authenticity, intimate relationships, soul-infused individual service, and creative risk and adventure" (p. 224). As a result, there are many uninitiated adults who have yet to be able to move from an egocentric to soulcentric orientation, and therefore demonstrate a form of pathoadolescence. I assert that the oppressive value hierarchies, centric thinking, and logic of domination detailed above emerge from a pathoadolescent and egocentric worldview that is self-interested and self-serving. To shift our mindsets and priorities, it is likely that a much greater emphasis be placed upon healthy human maturation and the healing of collective and developmental traumas that have arrested our growth.

For an ecocentric-as opposed to egocentric-culture to emerge, Plotkin (2008) asserts that adults need support with soul initiation. Such initiation support would reorient egocentric adults toward realizing their soul's purpose in service to the ecological and social worlds and would set them upon a lifelong journey toward personal and relational fulfillment. Similarly, children need the nurturance of soulcentric adults who can help them to maintain their wild nature and identify their soul's unique niche or purpose through a connection with the earth and the greater intelligence in which we participate. This necessitates that children and adults maintain an intimate relationship with nature through solitary immersions where they can learn their soul's purpose at ever-deepening levels.

How might music education support human maturation and further discovery of one's soul purpose? First, we could embrace sound-ecology and sensory cultivation as a means to enliven both our relationship with the earth as well as our sensory awareness. Second, we could resist practices that cut us off from our relationship with or identity as the earth, and embrace practices that connect us more deeply to our local watersheds, topography, and the flora and fauna who comprise our immediate ecosystem (Shevock, 2018)—which goes hand-in-hand with connecting with the musicians and musicmaking that happens in our local communities. Third, we could remove egocentric purposes for music making based upon competition and social comparison and replace them with opportunities for authentic expression and intimate relational dialogues (Hendricks, 2018). Fourth, we could embrace the spiritual purposes of music engagement that, along with solitary nature encounters, could further support soul initiation and realization. Specifically, we could explore Boyce-Tillman's (2020) notion that music education practices support the cultivation of all five of the interacting domains of music experience (materials, expression, construction, values, and spirituality/liminality) as a means to realize eudaimonic aims. If we consider Plotkin's (2008) assertion that both adults and children need support to flourish into soulcentric persons, then prioritizing relevant experiences within music education seems 
critical if our aim is to nurture the capacity for more humans to hold a ecocentric worldview compatible with human flourishing.

\section{EDUCATION FOR THE ENVIRONMENTAL AND SOCIAL COMMONS: TOWARD AN EARTH DEMOCRACY}

All of the individual concerns addressed above should be seen as contributing to, and integrated with, a much more collectivist and community-oriented way of thinking. As Figueres and RivettCarnac (2020) assert, it will be necessary for our survival to create community-based collaborative systems that are sustainable both in regard to our local bioregions and within the global ecosystem. To do so, we might consider the concept of the environmental and cultural commons. The environmental commons can be understood to be non-enclosed (not privately owned) lands, seeds, and other natural elements that are free to access and open to everyone. Similarly, the cultural commons can be understood to be places, venues, archives, collections, and resources that are free and accessible to all. Martusewicz et al. (2015) see schools as a location for reclaiming the environmental and cultural commons and to create "a community-based self-reliance model that honors reciprocity, mutual care, and sharing" (p. 211). Such an effort could interrupt the replication of unsustainable practices and social inequities though a shifting of egocentric purposes of education (such as career preparation and a means to climb the socio-economic ladder) to one focused upon gaining "systemic wisdom where learning is oriented toward understanding and acknowledging the ways in which we interact with, depend upon, and impact a larger system of intelligence" (p. 212).

The aim to reclaim the environmental and cultural commons aligns with the first of Smith and Silverman's (2020) three pathways to embody eudaimonic ideals, in that this relational and community-based way of living is necessarily situated within the global context and is concerned with equity and justice.

Educating for the commons is a specific way of ensuring that communities flourish by emphasizing that an important knowledge base of skills, craft, tradition, relationship patterns, and decision-making practices that are more in balance with the needs and processes of our ecosystems will not be lost (Martusewicz et al., 2015, p. 285).

Education for the commons can be seen as a way to create and maintain sustainable and resilient community systems that are regenerative and just.

For music educators to educate for the commons, we may need to revision our roles within this more collaborative structure. Musicians and music educators have traditionally acted as culture bearers and reproducers. As active participants in the environmental and cultural commons, it will be important to consider the role of a culture maker who creates culture with other human and other-than-human actors rather than participating in colonial practices, or what Fisher (2013) considers the buying and selling of weakened forms of culture as if they were a commodity. Culture making within the environmental and cultural commons aligns with Shevock's (2015) eco-literate pedagogy in that music is connected to "local places," is "connected with nature in meaningful and ethical ways," promotes "ecological consciousness by ritualizing and creating music rooted in soil," and connects music makers to the planet by connecting the local to the global (p. 11). While facilitating music within the commons will require music educators to shift to the role of a collaborative culture maker, music educators might also consider how musical and storytelling traditions may contain local knowledges about the ecology and how to live sustainably within the bioregions. In this case, more traditional culture-bearing roles might be appropriate as long as they are used to fortify the commons through a sharing of knowledge rather than an imposition of only dominant cultural forms upon the community. Where indigenous and local traditions have been erased, music educators might work to reconstruct such knowledge through music composition and community art making (Martusewicz et al., 2015).

While the specific conceptions of the environmental and cultural commons outlined above highlight the importance of sharing both knowledge and the collective stewarding of our shared bioregions, central to both ideas is the assumption that the commons serve the common good rather than undermine community and contribute to ecocide. Martusewicz et al. (2015) emphasize that a collective effort will need to be made in order to "teach each other how to identify what is useful and mutually beneficial in our commons and what is harmful" (p. 284) and to replace egocentric habits and remove the logic of domination.

In Humane Music Education for the Common Good (Yob and Jorgensen, 2020), music education scholars consider how a humane music education might contribute to the common good. Drawing from several UNESCO reports on education, Yob (2020) reports that notions of a humanist-informed approach to education are outlined that depict a humane form of education as a means to realize the outcome of common $\operatorname{good}(\mathrm{s})$. It is important to note that, although the UNESCO reports offer some gestures toward a more holistic education, the vision is largely anthropocentric and does not reposition education as participation within a "larger system of intelligence" (p. 212) that includes the wisdom of the earth and other-than-human entities. That said, notions of humane education for the common good are likely beneficial to consider in the effort to expand the cultural commons.

To expand from anthropocentric ideas and to envision a better integration of the environmental commons and cultural commons, I turn to Shiva's (2005) ten principles of earth democracy:

1. All species, people and cultures have intrinsic worth.

2. The Earth community is a democracy of all life.

3. Diversity in nature and culture must be defended.

4. All beings have a natural right to sustenance.

5. Earth democracy is based on living economies and economic democracy.

6. Living economies are built on local economies. 
7. Earth democracy is a living democracy.

8. Earth democracy is based on living cultures.

9. Living cultures are life nourishing.

10. Earth democracy globalizes peace, care, and compassion (pp. 10-11).

Central to Shiva's ideas is the notion that other living-beings are an integral part of our communities; that the ecological processes that sustain life (food, water, health, education, and livelihood) are fundamental human rights, and that economic activities should not interfere with the renewal of living systems (Martusewicz et al., 2015). Enacting the principles of earth democracy would require educators to move to a much more participatory form of democratic practice where students, community members, and other-than-human actors are given equal voice in decision making. It would also require that beliefs and practices based upon the logic of domination be questioned and replaced with ones more equitable, humane, and inclusive. To apply Shiva's ideas to music education, it would be important to decentralize practices such as the interpretation of previously composed music and the conductor-led ensemble-both which impose the musical will of a few persons-to make room for musical collaborations that are equally negotiated between the students, teacher/facilitator, and the current cultural and ecological contexts.

\section{REROUTING OUR ENERGY TOWARD FLOURISHING}

I have outlined a re-visioning of music education that could provide the necessary interdisciplinary and experiential learning for children to maintain their sense of wonder in nature; to fully develop their sensory capacities; to maintain, and if necessary, repair their mental health; and to attune more carefully to their wild nature and soul's purpose. I have also situated these individual concerns as integral to the collective project of stewarding and regenerating the environmental and cultural commons toward an earth democracy. Such a vision rejects

\section{REFERENCES}

Adams, D., and Beauchamp, G. (2018). Portals between worlds: a study of the experiences of children aged 7-11 years from primary schools in wales making music outdoors. Res. Stud. Music Educ. 40, 50-66. doi: 10.1177/ $1321103 X 17751251$

Akbari, E. (2016). Soundscape compositions for art classrooms. Art Educ. 69, 17-22. doi: 10.1080/00043125.2016.1176480

American Association for Cancer Research (2020). Air Pollution May be Associated With Many Kinds of Cancer. Philadelphia, PA: AACR.

American Psychological Association (2017). Mental Health and Our Changing Climate: Impacts, Implications, and Guidance. Washington D.C: APA.

Bates, V. C. (2013). Music education unplugged. Action Crit. Theory Music Educ. $12,75-90$.

Black, A. M., and Bohlman, A. F. (2017). Resounding the campus: pedagogy, race, and the environment. J. Music Hist. Pedagogy 8, 6-27.

Boyce-Tillman, J. (2004). Towards an ecology of music education. Philos. Music Educ. Rev. 12, 102-125. doi: 10.1353/pme.2005.0013

Boyce-Tillman, J. (2016). Experiencing Music - Restoring the Spiritual: Music as Well-Being. London: Peter Lang. egocentric purposes of education and the logic of domination that underpin injustice and ecocide and embraces soulcentric and ecocentric approaches that are more likely to ensure human and other-than-human flourishing.

Smith and Silverman's (2020) three pathways-which they assert provide a means to "be an ethical, loving, compassionate educator, co-learner, student, facilitator, participant, and maker of music" (p. 6) - align well with such a vision. The radical revisioning of music curricula I propose above calls musicians to better understand their place in the global ecosystem and to learn how to, as Smith and Silverman (2020) suggest in their first pathway, "envision and act for a more equitable and just world" (p. 6) - the primary purpose of an ecojustice education. Furthermore, the maintenance of the cultural and environmental commons provides greater opportunities to realize the second pathway where the aim is to "curate mutually flourishing communities" (p. 6) where members thrive and co-create meaning. The individual purposes (including the preservation of a sense of wonder in nature, the full development of sensory capacities, psychospiritual wellbeing, and soulcentric maturation) all support the conditions needed for flourishing through music learning - the aim of the third pathway-and expand the spaces for music making to include nature. Perhaps with such eudaimonic aspirations we might foster the collective energy to make the radical changes that ensure that human civilization flourishes within the regenerative capacity of the living ecosystem.

\section{AUTHOR CONTRIBUTIONS}

The author confirms being the sole contributor of this work and has approved it for publication.

\section{FUNDING}

This publication was funded by the Boston University.

Boyce-Tillman, J. (2020). “An ecology of eudaimonia," in Eudaimonia: Perspectives for Music Learning, eds G. D. Smith and M. Silverman (London: Routledge), 71-89. doi: 10.4324/9780429264948-7

Brown, M. Y. (2016). "Supporting children emotionally in times of climate disruption: teaching practices and strategies," in Education in Times of Environmental Crises, ed. K. Winograd (London: Routledge), 195-209. doi: 10.4324/9781315671970-23

Burke, S. E. L., Sanson, A. V., and Van Hoorn, J. (2018). The psychological effects of climate change on children. Curr. Psychiatry Rep. 20:35. doi: 10.1007/s11920018-0896-9

Buzzell, L., and Chalquist, C. (2019). It's Not Eco-Anxiety - It's Eco-Fear!: a Survey of the Eco-Emotions. Available online at: http://www.chalquist.com/its-not-ecoanxiety-its-eco-fear-a-survey-of-the-eco-emotions/ (accessed April 6).

Carson, R. (1956). The Sense of Wonder: a Celebration of Nature for Parents and Children. New York, NY: HarperCollins.

Centers for Disease Control and Prevention (2020). Data and Statistics on Children's Mental Health. Atlanta, GA: CDC.

Cohen, M. J. (1997). Reconnecting With Nature. Tongi: Ecopress.

Environmental Protection Agency (2018). The Links Between Air Pollution and Childhood Asthma. Washington, D.C: United States Environmental Protection Agency. 
Figueres, C., and Rivett-Carnac, T. (2020). The Future we Choose: Surviving the Climate Crisis. New York, NY: Vintage.

Fisher, A. (2013). Radical Ecopsychology: Psychology in the Service of Life. Albany, NY: State University of New York Press.

Friesen, D. (2012). Starting with soundscape. Can. Music Educ. 53:9.

Galloway, K. (2017). Making and learning with environmental sound: maker culture, ecomusicology, and the digital humanities in music history pedagogy. J. Music Hist. Pedagogy 8, 45-71.

Gibson, J. L., Cornell, M., and Gill, T. (2017). A systematic review of research into the impact of loose parts play on children's cognitive, social and emotional development. Sch. Ment. Health 9, 295-309. doi: 10.1007/s12310-017-9220-9

Harvard T. H. Chan School of Public Health (2020). Climate Change and Mental Health. Boston, MA: Harvard.

Heckel, S. (2017). Soundscapes: using informal learning pedagogy to create a Canadian strand of musical futures. Can. Music Educ. 58, 12-16.

Hendricks, K. S. (2018). Compassionate Music Teaching. Lanham, MD: Rowman \& Littlefield.

Huovinen, E., and Kuusinen, V. P. (2006). Soundscapes and verbal images as referents for music students' free improvisations. Musiikkikasvatus/The Finnish J. Music Educ. 9, 18-32.

Imada, T. (2019). "Soundscape, sound education, and the grain of the music: experiencing the luminousness of music being what it is," in Creativity in Music Education, eds Y. Tsubonou, A.-G. Tan, and M. Oie (Berlin: Springer), 35-45. doi: 10.1007/978-981-13-2749-0_3

Intergovernmental Panel on Climate Change (2020). Special Reports. Geneva: IPCC.

Jennings, P. A. (2019). The Trauma-Sensitive Classroom: Building Resilience With Compassionate Teaching. New York, NY: W. W. Norton.

Louv, R. (2008). The Last Child in the Woods: Saving our Children From NatureDeficit Disorder. Chapel Hill, NC: Algonquin Books.

Louv, R. (2012). The Nature Principle: Reconnecting With Life in a Virtual Age. Chapel Hill, NC: Algonquin Books.

Macy, J., and Brown, M. (2014). Coming Back to Life: the Updated Guide to The Work that Reconnects. Gabriola, BC: New Society Publishers.

Martusewicz, R. A., Edmundson, J., and Lupinacci, J. (2015). Ecojustice Education: Toward Diverse, Democratic, and Sustainable Communities, 3rd Edn. London: Routledge.

Matsunobu, K. (2013). Peforming, creating, and listening to nature through music: the art of self-integration. J. Aesthetic Educ. 47, 64-79.

MayDay Group (2020). Action Ideals. Available online at: http://www. maydaygroup.org/about-us/action-for-change-in-music-education/ (accessed April 6).

Miron, O., Yu, H., Wilf-Miron, R., and Kohane, I. S. (2019). Suicide rates among adolescents and young adults in the United States, 2000-2017. JAMA 321, 2362-2364. doi: 10.1001/jama.2019.5054

Mojtabai, R., Olfson, M., and Han, B. (2016). National trends in the prevalence and treatment of depression in adolescents and young adults. Pediatrics 13, 1-12. doi: $10.1542 /$ peds.2016-1878

Morton, C. A. (2012). "Music education for "all my relations," in The Oxford Handbook of Philosophy in Music Education, eds W. Bowman and A. L. Frega (Oxford: Oxford University Press), 472-491.

O’Donohue, J. (2015). Walking in Wonder: Eternal Wisdom for a Modern World. New York, NY: Convergent.

Orr, D. W. (1992). Ecological Literacy. Manhattan, NY: University Press of New York.

Orr, D. W. (2020). "Musicophilia, biophilia, and the human prospect," in Eudaimonia: Perspectives for Music Learning, eds G. D. Smith and M. Silverman (London: Routledge), 50-59.

Pijanowski, B., Villanueva-Rivera, L., Dumyahn, S. L., Farina, A., Krause, B., Napoletano, B. M., et al. (2011). Soundscape ecology: the science of sound in the landscape. BioScience 61, 203-216. doi: 10.1525/bio.2011.61.3.6

Plotkin, B. (2008). Nature and the Human Soul: Cultivating Wholeness in a Fragmented World. Novato, CA: New World Library.

Plumwood, V. (2002). Environmental Culture: the Ecological Crisis of Reason. London: Routledge.
Recharte, M. (2019). De-centering music: a "sound education. Action Crit. Theory Music Educ. 18, 68-88.

Rosenberg, M. B. (2003). Life-Enriching Education. Encinitas, CA: Puddledancer Press.

Schafer, R. M. (1977). The Tuning Of The World: a Pioneering Exploration into the Past History and Present State of the Most Neglected Aspect of our Environment: the Soundscape. New York, NY: Random House Inc.

Shevock, D. J. (2015). The possibility of eco-literate music pedagogy. Top. Music Educ. Prax. 2015, 1-23.

Shevock, D. J. (2018). Eco-Literate Music Pedagogy. London: Routledge.

Shiva, V. (2005). Earth Democracy: Justice, Sustainability, and Peace. Boston, MA: South End Press.

Smith, G. D., and Silverman, M. (2020). "Eudaimonia: flourishing through music learning," in Eudaimonia: Perspectives for Music Learning, eds G. D. Smith and M. Silverman (London: Routledge), 1-13.

Snyder, E. (2018). Songs of Exploration, Exploitation, and Experience: Towards an Ecologically Literate Vocal Repertoire (Publication No. 10937118) Master's thesis. Chicago, IL: Northeastern Illinois University. (ProQuest Dissertations and Theses Global).

Spratt, D., and Dunlop, I. (2019). Existential Climate-Related Security Risk: a Scenario Approach. Melbourne, Vic: Breakthrough - National Centre for Climate Restoration.

Swiss Re Group (2020). A Fifth of Countries Worldwide at Risk from Ecosystem Collapse as Biodiversity Declines, Reveals Pioneering Swiss Re Index. Zurich: Swiss Re.

Vaugeois, L. C. (2019). Ecoliterate music pedagogy. Music Educ. Res. 21, 608-609. doi: 10.1080/14613808.2019.1647156

Ward, K. S. (2009). Musical soundscape: teaching the concepts of R. Murray Schafer to elementary students. Can. Music Educ. 50, 40-42.

Warren, K. (1998). "The power and the promise of ecological feminism," in Environmental Philosophy: From Animal Rights to Radical Ecology, eds M. E. Zimmerman, J. Baird Callicott, G. Sessions, K. J. Warren, and J. Clark (Upper Saddle River, NJ: Prentice Hall), 325-344.

Waters, J., and Maynard, T. (2010). What's so interesting outside? a study of child-initiated interaction with teachers in the natural outdoor environment. Eur. Early Child. Educ. Res. J. 18, 473-483. doi: 10.1080/1350293X.2010.52 5939

Weyhenmeyer, G., Steffen, W., Chan, K., Yin, P., Tao, Y., Peter, K., et al. (2020). A Warning on Climate and the Risk of Societal Collapse. Available online at: https://www.theguardian.com/environment/2020/ dec/06/a-warning-on-climate-and-the-risk-of-societal-collapse (accessed April 6).

World Health Organization (WHO) (2020). Climate Change. Geneva: WHO.

Yob, I. M. (2020). “There is no other," in Humane Music Education for the Common Good, eds I. M. Yob and E. R. Jorgensen (Bloomington, IN: Indiana University Press), 17-28.

Yob, I. M., and Jorgensen, E. R. (eds) (2020). Humane Music Education for the Common Good. Bloomington, IN: Indiana University Press.

Younker, B. A., and Bracken, J. (2015). Inquiry-based learning through birdsong: an interdisciplinary project-based experience. J. Music Teach. Educ. 24, 37-52. doi: $10.1177 / 1057083714527110$

Conflict of Interest: The author declares that the research was conducted in the absence of any commercial or financial relationships that could be construed as a potential conflict of interest.

The reviewer JB-T declared a shared research group with the author at the time of review.

Copyright (อ) 2021 Smith. This is an open-access article distributed under the terms of the Creative Commons Attribution License (CC BY). The use, distribution or reproduction in other forums is permitted, provided the original author(s) and the copyright owner(s) are credited and that the original publication in this journal is cited, in accordance with accepted academic practice. No use, distribution or reproduction is permitted which does not comply with these terms. 